\title{
A sisterhood of letters
}

\author{
Solidarity on the horizon of feminist thought
}

S olidarity has been a key topic for feminist thinkers of different times, schools and places. More than other disciplines, feminist theorists have dwelled upon the role of theory in the achievement of political and social goals. Calls for global sisterhood have incited proliferating debates as to the basis for solidarity between women and feminists. Theoretical disputes arising from the spread of deconstructionist ideas since the 1990s have led to a practical perplexity as to how to set feminist political goals if the category of woman is no longer straightforward. This article looks at how expectations for practical usefulness have resonated in feminist debates on solidarity and, drawing on Paul Ricoeur's ideas of textuality and interpretation, reflects on the process of interaction between feminist theory and feminism as a social movement. It argues that in spite of the apparent lack of unanimity, or even outright hostility, that theoretical controversies might seem to indicate, the multiplicity of viewpoints and positions that various feminist theories collectively entail is a necessary vehicle for creating more solidarity between women in and outside academia in the contemporary world. Looking towards the future of feminist theory, the article invokes the metaphor of a sisterhood of letters to reflect on the value of shared intellectual endeavour in building solidarities between women of different social, racial, religious and cultural backgrounds. ${ }^{1}$

1 This article is based on research supported by the European Regional Development Fund.

\section{Introduction}

The topic of solidarity has been a thorny one in the history of feminist thought. In 1949, Simone de Beauvoir notes: 'they [women] are united by a mechanical solidarity only insofar as they are similar: they do not share that organic solidarity upon which any unified community is founded ...' (2011: 638). A few pages later, she illustrates this thought with an observation that during various wars, women have been the ones who were the most belligerently inflamed, compensating for their inactivity in war with all the more intense aggression towards the enemy: 'in victory they are as wild as hyenas against the beaten enemy; in defeat, they bitterly refuse any arrangement' (ibid. p. 642). Still, characteristically for Beauvoir, she makes a careful distinction between her descriptions of the status quo and her assessment of its social causes: 'Many of the faults for which they [women] are reproached ... simply express the fact that the horizon is blocked for them,' she concludes (ibid. p. 643). In this article, I would like to take another look at Beauvoir's concept of organic solidarity and reflect on its specific meaning in the context of feminist thinking. I am interested in establishing whether and how the unblocking of women's horizons has trans- 
lated into more organic solidarity between them and what are the conditions for this process to continue and flourish. More specifically to academic feminism, I am curious as to what form a 'unified community' of feminist theorists could possibly take.

\section{From feminism to feminisms}

Since Beauvoir's statement, made in the middle of the last century, a lot has happened that should make a difference as to both the horizons of women and solidarity between them. For decades now, Beauvoir herself has no longer been seen as the mother of modern feminism and her ideas have gone through both a fall into neardereliction and a subsequent revival (Bauer 2001: 3). Alongside the social and political advancement that has taken place during that time, feminist theory has blossomed into a field of study with global reach. It now draws on diverse ideas originating in indigenous cosmologies, African feminist knowledge, Latin-American feminist theory, Western philosophy, Southern theory - and the list goes on. In spite of this expansion being an inherently positive development, it has also brought along with it new worries: the simultaneous existence of various feminist positions has caused the discipline to appear splintered and suspect, so that it is no longer easy, fun, empowering, or even possible to take $a$ feminist position' (MasciaLees and Sharpe 2000: 3, italics in original). In parallel, attempts to account for these contradictions and conflicts have become increasingly problematic since '... any such definitions or histories are never finally able to apprehend the full complexities of feminist thinking and its practices. As a result, inevitably such efforts to relay definitions and histories of feminist groups are overly reductionist and simplistic, at times unwittingly perpetuating such divisions' (GrayRosendale and Harootunian 2003: 2).
Throughout these developments, feminism and solidarity have fared as somewhat strange bedfellows. Solidarity has been lauded as a necessary ideal and criticised as too superficial a goal. Whereas in general moral theory solidarity has enjoyed relatively modest theoretical interest, debates on female and feminist solidarity abound in feminist theory, pointing to its perceived importance for advancing feminist causes (Scholz 2008: 10). At the same time, it has been one of the most controversial issues within the discipline, characterised by sharp differences of opinion and calling into question the possibility of finding common ground between the proponents of different strands of the feminist movement and thought. Looking back at how attentive to solidarity-related concerns feminist theory has been throughout its short history, and how much theoretical effort has been put into correcting the oversights and misapprehensions made in the course of this work, it is hard to disagree with bell hooks's observation that there is no other movement for social justice that has been as self-critical as the feminist one (2015: xiv). Solidarity has been felt to be problematic in and between all areas of what Chandra Mohanty identifies as levels of feminist practice: the level of daily life where everyday acts constitute identities and relational communities; the level of collective action in groups and movements that share feminist visions for social change; and the levels of theory, pedagogy, and textual creativity involved in the scholarly and writing practices of the production of knowledge (Mohanty 2003: 5-6).

Beauvoir's differentiation between mechanical and organic solidarity, referred to above, seems at first sight to belong to the everyday level of interaction between women, but actually pertains to all the areas identified by Mohanty. Beauvoir's 
distinction (that probably originates in Durkheim, cf. Scholz and Mussett 2005: 53) matches mechanical solidarity with ties based on similarity, and organic solidarity with individuation and difference. Beauvoir's critique of similarity as an untenable ground for genuine solidarity has been voiced in various forms later on. During the 1980s, Audre Lorde, Toni Morrison, bell hooks, and several others, demonstrated that the idea of feminist solidarity developed by white activists did not adequately take into account the concerns of women of colour, who in addition to gender-related issues experienced also racial and classbased oppression much more severely than white women. For women of colour, mainstream feminism offered little support and guidance because it overlooked the cultural and social differences due to which many feminist concerns appeared in a different light for them. In a preface to the 2015 third edition of her book Feminist Theory from Margin to Center (originally published in 1984) bell hooks writes:

Nowadays it has become so commonplace for individuals doing feminist work to evoke gender, race, and class, it is often forgotten that initially most feminist thinkers, many of whom were white and from privileged class backgrounds, were hostile to adopting this perspective. Radical/revolutionary feminist thinkers who wanted to talk about gender from a race-sex-class perspective were accused of being traitors, destroying the movement, shifting the focus. Often our work was ignored or ruthlessly critiqued, deemed not scholarly enough or too polemical. (hooks 2015: xiv)

In a similar vein, postcolonial theorists have denounced the idea of global sisterhood on grounds of its universalism which fails to address the differences between third-world women for whom such solidarity looks good only in theory, whereas in practice their problems and concerns are far too divergent and varied to be solved through bunching them into a single category (Mohanty 1988). More specifically, the idea of inclusion has been put to the test by comparing sisterhood to a nation state that hypocritically tries to include all women, whereas not all are actually welcome:

... the ultimate rationale of the politics of difference is cast in terms of an overall politics of inclusion: the desire for an overarching feminism to construct a pluralist sisterhood which can accommodate all differences and inequalities between women. ... Feminism functions as a nation which 'other' women are invited to join without disrupting the ultimate integrity of the nation. (Ang 2003: 203)

From Latino and queer perspectives, the same idea has been voiced indicating the undesirability to be included as a token or merely an interesting example: 'As Chicanos we know and understand that although we encourage a politics of solidarity with other marginalised groups we cannot allow anyone else to write our (hi)stories or regulate our cultural production' (Hames-García and Martínez 2011: 141).

Various poststructural and postmodern approaches have also added their share into the complexity of the problem. Over the years, the deconstructionist critique of subjectivity has become increasingly antagonistic towards more phenomenologically-minded approaches that saw value in the analysis of direct experience. 
But alongside a careful attempt to avoid theory that would grow out of a particular experience and therefore risk being partial and exclusionary, poststructuralist feminism provoked the old question of theory versus practice to reappear. It was now felt that feminist scholarship and theory had become far removed from the lives of most people in society, who tended to view feminist thinking as rarified and irrelevant (hooks 2015: Xv). Feminist solidarity came to be seen as problematic not because of the vices of neoliberalism, capitalism, patriarchy, etc. that would disrupt natural networks of cooperation between women, but because no agreement could in principle be reached on who or what is a woman: '... lately it seems that feminist theorists are obsessed with the question whether there are really "women" (or just "differences") in ways that threaten to become irrelevant to any practical political goal' (Bartky 2002: 2). Ann Ferguson has worded the solidarity problem as a strategic political and theoretical question: 'if we reject essentialism and acknowledge that women have many power and privilege differences that enter into their political priorities and frame their interests, how can feminist women and men unite across these differences to challenge patriarchal social structures that promote gender injustice?' (Ferguson 2009: 162).

\section{Horizons of solidarity}

It seems then, somewhat paradoxically, that less than a century after Beauvoir's assessment that women were not intrinsically different enough for solidarity to grow organically between them, the situation has reversed and the differences have grown too big for solidarity to be possible. However, there seems to be an inconsistency in this reasoning. According to Beauvoir, solidarity between women had been impeded because their opportunities for leading an intellectually varied and meaningful life used to be limited due to lack of education and being confined to the home and care work where ties of solidarity could only be based on similarity. The life prospects that women had at that time were so alike and indistinguishable, with so little variation and diversity, that it caused women also to be similar and homogeneous. Nowadays, however, this should no longer be the case. Compared to the time of Beauvoir's writing, one cannot but recognise the extraordinary widening of women's horizons in both social and academic spheres. As already mentioned above, feminist theory has grown into an international and interdisciplinary field of study that continues to find new and rediscovered sources of inspiration for scholarly research. By now, there is no agreement within the discipline on how to define feminism, and encyclopaedia entries on the problematics of definition alone take up tens of pages (cf. McAfee 2018). In itself, this is obviously a sign of the considerable scope and strength that feminism, both in its academic and non-academic forms, has gained by now. The fact that there are so many different and competing understandings of what feminism is and does bears witness to its inner multiplicity and pluralism that ultimately should translate into a multiplicity of possibilities for being in the world, compared to the limited opportunities that being a woman meant even only a few generations ago. Following Beauvoir's analysis, this should slowly but steadily contribute to increased solidarity between women as they more and more organically enter the different roles and social positions available in a more equal society where the category of woman is no longer closed but open for inquiry and debate. If it now still looks like solidarity between women and feminists is problematic, it is worthwhile 
to reflect on whether it is indeed the differences between them that are to be blamed for shortcomings in solidarity. After all, on Beauvoir's account, such multiplicity was to be desired as one of the critical preconditions for achieving organic solidarity.

To take a closer look at how the process of organically developing solidarity could take place, it seems useful to break the concept of horizon (as used by Beauvoir) into two and consider it from two different perspectives - space and time - so that the interaction between the two would become clearer. The multiplication of views and theoretical positions described above would in that case constitute the spatial horizon of feminist thought. At first sight, the temporal horizon remains invisible, figuring as a 'natural' backdrop to the events initiated by actors contributing to the broadening and diversifying of the spatial horizon. But at a closer look it seems that the historical conditions in which feminism as a theoretical discipline has developed have played an important role in its keen interest in solidarity-related issues. Feminism in most of its present shapes and shades has its roots in a fight for social justice, that is, in radical activism. A militant tone and assertive or, if necessary, aggressive conduct were the name of the game in the days when women had to stand up for basic rights such as the vote, education and bodily integrity. What this situation demanded was decisiveness, standing firm for one's goals. In order to break through to the public sphere, the common perception of women as submissive and obedient creatures in need of male custody had to be broken. The fervent atmosphere in which feminist theory as a discipline has developed has fostered the expectation that it should directly contribute to the fight against the oppression of women in patriarchal societies. This situation of urgent practicality has considerably affected and shaped feminist theory: both in the choice of the problems that it has been dealing with, as well as those that it has encountered inside the discipline. Theory has routinely been expected to provide 'usable' answers to very grave practical problems, including social and global problems relating to poverty, racism, homophobia, development aid, etc. The requirement to be beneficial for a practical struggle against various forms of oppression is very much present also nowadays even in the most philosophical strands of feminist thought. It is only in comparison with other disciplines that we realise that this dilemma of usefulness of theory presents itself here much more starkly than in other fields of theoretical reflection. Surely this expectation is not unwarranted, but there is probably no other field where such assumptions are so strong. If a non-feminist philosopher were asked whether their theoretical work contributed to the eradication of global poverty, they would normally be quite confused or even upset. In feminist theory, the authors' awareness of their (even if only self-assumed) moral duty to benefit society at large is remarkable. However, as is known from phenomenological accounts of experiencing time, if something is actively awaited and hoped for, its arrival feels all the more to be lagging and delayed.

In addition to the aspect of expectation, the importance of the temporal horizon stands out when we think about how the theoretical work done on the spatial horizon actually comes to life and enters lived experience in the sense understood in phenomenological philosophy (Given 2008: 616-17). To elucidate this process, I turn to the thoughts of Adrienne Rich (1929-2012) and Paul Ricoeur (19132005), who have given careful consideration to the ways that theory is created and 
how it helps us to make sense of the world we inhabit. Adrienne Rich has once articulated what I would, in the present context, like to call an ecosystem of theory: 'Theory - the seeing of patterns, showing the forest as well as the trees - theory can be a dew that rises from the earth and collects in the rain cloud and returns to earth over and over. But if it doesn't smell of the earth, it isn't good for the earth' (Rich 2003: 31). In human sciences, theory is grounded in and coloured by experience. In the process of abstraction, theory rises above the experience and from this overlooking position can reach and achieve more than it could had it stayed close to the ground. However, from high up it has to return to the earth and be tested against the material circumstances that have already changed in the meantime; be it as a consequence of this very same theory, or simply because time has gone by during the period of its maturation. From this reality check, it can move up again, to gather new insights, new ideas. The productivity and creativity of this process is greater the more the theory is able to carry with it 'the smell of the earth' - the acuteness and concreteness of the problem it is trying to unravel.

Paul Ricoeur, who, incidentally, is generally known also for seeking cooperation and the building of bridges between different philosophical theories (Simms 2002: 1), has expressed similar ideas in his analysis of hermeneutics and interpretation. According to Ricoeur, along with other phenomenological philosophers of the last century, every question concerning any being is a question of the meaning of that being (Ricoeur 2016: 74). What philosophy can do is to pay attention to the distance, the empty space that is necessary for interpreting any lived experience, because theory, along with fiction, poetry and other forms of text, ultimately works on the linguistic expression of experience: 'Experience can be said, it demands to be said. To bring it to language is not to change it into something else, but, in articulating and developing it, to make it become itself' (ibid. p. 75). Thus, theory has the potential to propose new meanings that are at the same time new possibilities for being. Texts carry in them a potential for a liberating autonomy because they create a conceptual space that opens up novel possibilities not only theoretically but also practically. However, for that to be possible, the conceptual world offered by the text needs to be interpreted, but not in order to discover its 'real' or implicit meaning, but to spread out the world offered by the text in ways that respond to the situation of the reader: 'What is to be interpreted in the text is a proposed world which I could inhabit and in which I could project my ownmost possibilities' (ibid. p. 72). A necessary precondition for the act of interpretation is the double distanciation that textuality makes possible. It frees the ideas contained in the text from the intentions of its author, and it enables the reader to relate to the thoughts of authors who are temporally and physically remote. The historical distance develops with the accumulation of traditions, conventions and heritage and so does the distance of the texts from their authors. There, yet another form of distanciation occurs that Ricoeur calls appropriation and that enables the 'distanciation of self from itself' in a process whereby the readers respond to the proposals of meaning that the text offers from their respective socio-cultural conditions. The space that is created at the crossroads of these three axes is the place where new ideas and new ways of being in the world can take shape. For any theoretical field, it is important to keep this space free and open. Once opened, it has the inner potential for growth and expansion that goes hand in hand with 
an increased ability of understanding the world for those who participate in the process of interpretation.

Ricoeur's model of distanciation, appropriation and understanding is one of many philosophical ways to phrase an ecosystem of theory. Here we recognise Rich's idea of the dew that rises from the earth, collects in the cloud, returns to the earth as rain, and the whole process starts anew. Texts interpret the experience of living in the world and by doing that they create new meanings that can be appropriated by the readers whose understanding of themselves will thereby improve. Together with this improvement, their experience changes and this will in turn get interpreted in texts that are there for new readers to discover and appropriate. What is crucial for this process, is the distance - first, from the object of study in order for it to be interpreted as the object in question, then from the author, as enabled by written texts, and finally from the reader herself as she situates her own experience in the 'theoretical space' created by the text. 'Distanciation, in all its forms and figures, constitutes par excellence the critical moment of understanding' (Ricoeur 2016: 74). At its best, theory will reach beyond the specific time and place of its creation, but it always occurs and finds expression in a specific time and place. One of the critical characteristics of the creation of theory is that its processes are time-consuming and require a systematic effort of many dedicated minds. Although mostly carried out individually, it is an inherently collective work, one that is essential for providing us with a relevant understanding of what it means to be a living being, a human, a woman, a man, somebody who cannot be defined as woman or man, etc.

On the general temporal horizon of theorising the experience of being human, systematic feminist thought is still very young. It can be compared to the periodic table in its initial phase, with only a few of the chemical elements already well defined and positioned. A large part of the substance that fills women's lives and experiences is still missing from its theoretical field; it is yet to be discovered and written. Although the number of pages of feminist theory published annually by universities, institutes and independent researchers is by now undeniably enormous, the apparent overabundance of this theoretical work is at least partly deceptive, again because what is needed for the development of a theoretical field is for the interpretation cycle to run its course over a prolonged period of time, such that the processes of creation, appropriation and understanding may yield new ways of inhabiting the world to which the readers can 'project their ownmost possibilities' (Ricoeur 2016: 72). But even more importantly, the possibilities for being otherwise that are created in the process of writing, whether it be in theoretical or literary mode, ultimately need time for becoming an organic part of the readers' experience. Thus, although in hindsight it can be said that feminist ideas have been around for centuries already, or that they have always been kindled in some form in the minds of enlightened people, it is only very recently that the social and political conditions have become favourable enough for women to be able to choose between, and accomplish, genuinely different life prospects, social roles and vocations that are no longer limited by their gender. And it is this constitutive, inherent difference that is necessary for organic solidarity to become possible so that it is not obstructed by jealousy and competition.

Although similarity of goals and ideals might at first sight be considered a prerequisite for solidarity, it is rather the 
historically-conditioned scarcity of genuinely different cultural modes of self-interpretation and self-articulation that is still hindering both female and feminist solidarity today. In principle, solidarity means support for the other in her fight or work or activity, as the case may be. In order to show solidarity, one has to be able to accept the goal of the other as a worthwhile objective to be achieved, even if this does not necessarily align perfectly with what they were currently doing on their own. Thus, both of these persons need to have an aim they can identify with, but, importantly, these aims, although they usually are compatible with each other, have to be in some significant aspects different, since otherwise the persons would rather be brothers-in-arms or co-workers, who are supposed to pursue the same goal by definition, and not as a sign of solidarity. (Intermediate cases can also be imagined, but are not important here.) Organic solidarity can occur between persons each of whom have their own position and goals they can identify as theirs with sufficient conviction and confidence. As pointed out by Sandra Bartky in reference to Max Scheler, we do not and need not share the exact feelings of those whom we join in solidarity. It is possible to commiserate with the other or take joy in their success, but we do not experience neither their suffering nor their joy, as these are unmistakably theirs. The necessary emotional distance we have from each other is not a hindrance but an enabler of solidarity (Bartky 2002: 80-1). A similar idea has been expressed by Jodi Dean, whose conception of reflective solidarity relies on the adoption of the perspective of a situated hypothetical third that provides a degree of distance and abstraction from affections, traditions and beliefs constructing us as selves (Dean 1996: 177). These and other more philosophical understandings of solidarity share the emphasis on the 'empty space' created by different forms of distanciation within the ecosystem of thought. Due to the relatively limited temporal horizon of feminist theory, it is sometimes still difficult to keep this conceptual space free and open. But theory has the ability to draw attention to problems that have hitherto gone unnoticed. What was before only felt, or maybe not even consciously registered in any way, now comes into sight because it is conceptualised, worded, phrased. 'It renders thematic what was only operative, and thereby makes meaning appear as meaning' (Ricoeur 2016: 77). What theory can provide for all women trying to negotiate their lives as participants in social, cultural, sexual, familial, racial, etc. relationships is more ways of making sense of their experiences by creating a necessary distance from them. As long as the space of self-articulation remains limited, there is a much greater chance of its inhabitants falling prey to ideological or dogmatic reactions and becoming as 'wild as hyenas against the beaten enemy'.

Solidarity understood in terms of difference and distanciation cannot be based on a hope to directly contribute to social justice, but feminist theory can create room for solidarity by cultivating as many theoretical positions as possible, so that women of different social, racial, class and religious backgrounds may find among them those that best reflect their experience. Being part of a fight against oppression, feminist theory has been keen to cultivate ideas that would be highly inclusive and promote solidarity between women of different backgrounds. It is as if various theoretical frameworks have been tested in search for one that would be the most inclusive. In retrospect it seems, however, doubtful whether theory can support solidarity in such a direct way. As long as feminist 
theory is seen mainly as a tool in the fight for social justice, it remains, in a sense, unfavourable to an inner growth of space for solidarity, exactly because of its tendency to be politically, and ideologically, laden. This is not because philosophy and politics would be somehow antithetical or mutually exclusive; but there are important aspects in which they differ decisively, since theory written directly in the name of creating a better world risks losing touch with that same world. In activism and political engagement, one can be justifiably convinced of the cause one is fighting for and therefore, no matter how hard the fight, it is always right to engage in it. It is the right thing to do. Any philosophical method, however, is premised on a radical doubt. This is not to say that feminist theorists should bring women's rights into doubt, or not be convinced that the fight for social justice is a noble thing. But a philosophical approach does carry a risk because there can be no guarantee that philosophy will render the 'right' feminist answer (Bauer 2001: 26). However, this doubt and risk are at the same time the conditions for a genuinely free debate since they are the conditions that hold the inner space within the discipline open. A text that lays claim to the 'right' feminist answer is clearly no longer theoretical, but ideological.

Thus, although it is true that different conceptualisations have given rise to different schools of thought that appear to be rather antagonistic, it is actually a very necessary phase of conceptual development as it nourishes the process of differentiation and individuation that is necessary for organic solidarity. A lack of inherent complexity and multiplicity within the conceptual field of feminist theory is likely to create false dilemmas of having to choose between one or the other theory, whereas all theories inevitably have their strengths and weaknesses, and strong theories can be conflicting but still complementary, working towards cultivating the theoretical field with increasing precision and care. It is this plurality of ideas and the healthy academic rivalry between competing, or even conflicting, positions that will eventually create and sustain the space where solidarity and productive cooperation can grow. It is neither possible nor necessary to search for solidarity by agreeing on the supremacy of one or another theory - be it phenomenology, postmodernism, posthumanism or something else - what is needed is a sustained proliferation of theoretical positions. On that account, feminist theorists implicitly all contribute to solidaritybuilding. Solidarity can be based on a shared understanding that feminist theoretical work is valuable per se, and not in comparison with, or in contrast to, other theoretical perspectives; and that women's perspectives, however diverse or even contradictory, all in all work towards and contribute to a clearer and better understanding of the workings of society and human existence. The fact that we cannot define what a woman is, or what are women's perspectives, is not an impediment to a debate on solidarity but a prerequisite for it, as this is what feminist theory is supposed to be doing - problematising womanhood, and by doing that problematising all assumptions and presuppositions about gender in society. All these texts create possible worlds, possibilities for phrasing and situating one's experience within the cultural patterns available in society. And it is there, in that work and in the new meanings thus created that theory as a generative ecosystem can build solidarity. 


\section{A sisterhood of letters}

In the last part of this discussion on thinking and building solidarity within feminist theory, I would like to dedicate some theoretical effort to envisaging ways to conceptualise the virtual locus of feminist theory as a hospitable and solidarity-building place - a certain sisterhood of letters. In the course of this article, I have argued for two different views on feminist thought. On the one hand, feminism has undergone an inner diversification and growth so that it is no longer possible to talk about a feminist position without accompanying this statement with an explanation as to what variety or school of feminism one is referring to. On the other hand, I have tried to show that due to its still limited temporal horizon, the ideas, conceptions and notions put forward for debate in the course of this process have not had time to mature and be integrated into everyday experience over a sufficiently extended period of time. Juxtaposed in this way, both of these horizons - spatial and temporal - seem to be progressing almost teleologically towards conditions favourable to the more organic solidarity referred to by Beauvoir. However, this is far from being the case. A genuine pluralism of ideas is rare even in academia and its cultivation requires firm dedication and devoted intellectual efforts of many people. In order to participate in this effort, the participants need to find some form of solidarity between themselves to facilitate the mutual support and group spirit necessary for collective work. Yet, due to the requirement to value that same plurality, solidarity between thinkers in a specific field of research cannot be anchored directly to the ideas that are its objects of study. As Nancy Fraser has put it in her reflections on a discourse ethic of solidarity, the specific content of solidarity between groups cannot be extrapolated from the current, inevitably pre-politicised experiences and idiolects of the concrete participants, since these are always likely to be the experiences and idiolects of only some of the participants (Fraser 1986: 426). However, solidarity can be practised on the level where the conditions that are necessary for the field to grow and flourish are created; that is to say, the ecosystem of that particular theory.

In the light of all that has been said above, it is not surprising that the concept of sisterhood has come to be met with a considerable degree of suspicion over the course of feminist history. Taking note of the dangers inherent in the use of this concept, I would still like to make room for the idea of a certain philosophical sisterhood that would not be modelled on the matrix of a nation state, but instead on the intellectual community of women who were part of the so-called 'republic of letters' (Respublica Litteraria), that was active in Europe before and around the age of Enlightenment:

The seventeenth-century republic of letters was not a place, or a polity, or a club for gentleman scholars. It was rather a heterogeneous, multi-faith, transnational and inclusive group fuelled by a shared desire to advance learning, and to discover the best pathway to knowledge. The citizens of the republic of letters were philosophers, poets, doctors, linguists, and theologians from cities across Europe, who created a shared intellectual identity - they were collegial scholars, connected by friendship, pedagogy, patronage, and learning. They pursued their investigations in a variety of ways and places for a variety of reasons, but the shared desire to know was the engine of that republic. Thus the republic of letters was rather an 
impossible, ambitious, and inclusive ideal. (Pal 2012: 10)

The historical republic of letters has been described by some as excluding women, but according to a recent in-depth study by Carol Pal, this was certainly not the case and intellectual women were an organic part of this community of ideas. Moreover, the group of women were not just included in the republic of letters, but were also regularly engaging with each other although their scholarly interests and backgrounds varied greatly. The time frame of their activity - roughly from 1630 to 1680 - included civil wars, religious conflicts and scientific breakthroughs. Their intellectual commonwealth was multinational and multi-religious, representing women of different class, intellectual and family backgrounds. They were actively communicating among themselves, sharing their thoughts, worries and discoveries via rich interpersonal contacts. Since women at that time could not practise any learned professions or officially participate in academic life, their intellectual family was tied together solely by their passion for knowledge and theoretical pursuits as their scholarly work had 'no worldly purpose whatsoever' (Pal 2012: 3-4).

Could this model, that I would call a sisterhood of letters, work in the context of present-day academic study in feminist theory? In a way, it already does: universities and research institutes are increasingly multinational; most of the scholarly work is done in a highly international setting that includes people of many different religious, and social and geographical backgrounds. At least ideally, this worldwide scene of mutual learning should function as a free marketplace of ideas quite similar to the republic of letters. As referred to above, in the feminist context concerns have been voiced as to whether metaphors of nation and citizenship are best placed to discuss diversity and inclusion. As I have also suggested in this article, the tensions between the political and philosophical goals of feminist theory have sometimes been counterproductive to the fostering of mutual support and solidarity between feminist theorists. Therefore, my idea of a sisterhood of letters as a virtual space would bring together scholars engaging in feminist theory, but not enact any formal criteria of participation other than interest in feminist ideas. It is not a political but a philosophical community, whose only criterion of existence can be a radical openness of thought. As a framework for philosophical analysis and reflection on different theoretical positions within feminist theory, the sisterhood of letters dwells in a space that is held open by the different modes of distanciation, one of which is a sustained practice of looking at objects, either material or mental, philosophically in a way that problematises womanhood with a fundamental curiosity towards the world, and a fundamental doubt concerning our knowledge of the world. It does not need a specific methodology; or rather, it can use any philosophical method, ranging from the feeling of wonder described by the ancients, to the epoché of phenomenology, or simply the unruffled and systematic weighing of arguments that characterises analytic philosophy. Such sisterhood can be global, not in the sense that globally acceptable goals and strategies are agreed upon, but in the sense that the ideas, interests and strategies of different localities around the world are globally available for discussion and critique. It does not mean that for every single question that is asked philosophically, there is, or has to be, a feminist answer. There are many questions for which gender does not matter. But there are also vast areas that are 
still under-researched and under-developed from a feminist point of view. What feminist theory can do is to keep its horizon of thought as open as possible and prevent the creation of ideological barriers.

The life of every human being is open to creating something that is totally unexpected. This means, inter alia, that a human being can never be exhaustively defined by their gender. Therefore, the solidarity practised in the sisterhood of letters should be open-ended, without being directly attached to a battle against any particular social setting or situation, not even patriarchy or the oppression of women. After all, how could one carry on one's feminist work without believing that someday these, too, will pass. Solidarity is to be found in valuing and upholding feminist thinking in whatever historical moment, even though at present the overcoming of gender injustice is a goal still to be achieved. Although a common dictionary definition of solidarity would mean unity or agreement of feeling or action among like-minded individuals, solidarity within the sisterhood of letters is not necessarily created by uniting likeminded people around a shared goal but by a possibility to unite radically unlikeminded people around their shared interest in inquiring into the sources and opportunities of feminist ideas - without having any specific goal in mind.

What are feminist ideas? Do we need to define them or at least try to describe them in any precise terms? Yes, but it is a special feature of any philosophy to ask questions about itself and be open to different understandings and interpretations as to what exactly is its object of study. For feminist theory, the questions of what is a woman, what is feminism and what is feminist theory or philosophy are therefore intrinsic and will continue to be asked alongside other, more specific questions. Although these questions themselves are timeless, answers to them vary greatly depending on who will undertake to respond, and when and where. It is a common interest in asking these questions at all times and in all places - and not an interest in a common answer that would suit all times and all places - that can be the basis for solidarity between feminists (of whatever gender) and indeed all those for whom it makes sense to call themselves women. As humans, we are constantly forced by changing circumstances to create new solutions to the questions that present themselves as problems we individually or collectively face. We actually do not know whether, as Sally Haslanger has put it, 'when justice is achieved, there will no longer be ... men or women' and whether at that point we 'won't need the concepts of race and gender to describe our current situation' (Haslanger 2012: 366). But I think it can be argued that it is a theoretical possibility. However, it can be one only on the condition that serious theoretical work will continue to be carried out on what it would mean to have a society where there literally are no men and women and, for that matter, whether and why that would be desirable. Whatever our theoretical preference for the place and meaning of gender in human life may be, without such theoretical endeavour it is unlikely to materialise, since without the philosophical distance taken from the object of study the necessary space where things could be otherwise, where the new situation could slowly take shape on the horizon, cannot emerge.

\section{Conclusion}

In this article, I departed from Simone de Beauvoir's distinction between mechanical and organic solidarity to reflect on the causes for the lingering common perception that solidarity between women as well 
as feminists is weak and complicated. For Beauvoir, female solidarity had been hampered by the narrowness of women's social and intellectual horizons, which caused the cooperation between them to be merely mechanical, that is to say, limited to ties based on similarity. During the seven decades that have passed since Beauvoir's writing, women's social and academic horizons have undergone a rapid broadening and diversification, but now it is rather the differences between women that are often cited as an impediment to solidarity. This seems contrary to Beauvoir's suggestion that organic solidarity is based on individuation and difference. However, Beauvoir's viewpoint is justified when we look at the preconditions for solidarity in the context of a larger process that could be called an ecosystem of theory. For that I proposed to view the concept of the 'horizon' from two different perspectives, spatial and temporal, to suggest that the rapid diversification of feminist ideas taking place on the spatial horizon has not yet been matched with a diversification of lived experience that occurs on the temporal horizon and is the more immediate precondition for organic solidarity. Feminist theory puts forward ideas, but it takes considerable time, often several generations, for these ideas to become an organic part of someone's life as no longer a mere theoretical alternative but as one of their actual life prospects. I used Ricoeur's concept of distanciation to elucidate the process of interpretation that is time-consuming but will ultimately feed into a more dense and more articulated conceptual framework that can provide the necessary bridges between controversial ideas and conflicting positions. In parallel with the interpretation cycle, the social fabric will grow stronger and accommodate subtler and more variable positions that are better equipped to overcome antagonism towards social others and achieve organic solidarity with them. Thus, although it might at first sight look as if potential conflicts accompanying the diversification of feminism as a theoretical discipline make it harder to achieve solidarity between its participants and it is often difficult to find common ground even between seemingly close positions, such a view is deceptive and a genuine plurality of ideas is a precondition for organic solidarity that thrives on individuation and difference. However, such plurality cannot be expected to emerge automatically as a by-product of the diversification of the spatial horizon its cultivation requires sustained attention and effort for which, in turn, the actors involved need to find some form of solidarity to overcome their inevitable disagreements. Such academic solidarity cannot be based on any of the more concrete ideas or systems of thought that are the discipline's object of study, but it can be founded on the principle of openness to ideas that holds the ecosystem of the field favourable for conceptual growth and diversity. As one of the possible ways to envisage such collective work, I used the metaphor of a sisterhood of letters modelled on the intellectual community of women participating in the Respublica Litteraria active in the seventeenth-century Europe. Surely, feminist theory is able to accommodate much more varied and divergent ideas, hypotheses and modes of thinking than it currently does. What the present article has aimed to contribute to this discussion is a two-pronged idea that on the one hand, solidarity cannot be secured by writing more inclusive theory, but at the same time, the act of writing theory is a solidarity-building exercise since it opens up possibilities and carves out new ways of inhabiting the world. 
Rita Niineste is a PhD student of philosophy at the University of Tallinn. She has BA degrees in English philology (Tartu University) and philosophy (Tallinn University), and an MA in cultural theory and philosophy (Tallinn University).

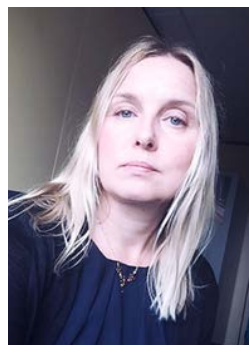

Her research focuses on feminist perspectives on sexual difference, as well as the philosophy of sexuality and sexual ethics. She is interested in the phenomenological analysis of empirical data yielded by experimental psychology and in prospects for science-based approaches to sexuality within the tradition of philosophy and beyond.

\section{References}

Ang, Ien. 2003 (1995). 'I'm a feminist but...: "other" women and postnational feminism, in Feminist Postcolonial Theory: A Reader, eds. Reina Lewis and Sara Mills (New York: Routledge), 190-206.

Bartky, Sandra Lee. 2002. 'Sympathy and Solidarity' and Other Essays (Lanham, MD: Rowman and Littlefield).

Bauer, Nancy. 2001. Simone de Beauvoir: Philosophy and Feminism (New York: Columbia University Press).

Beauvoir, Simone de. 2011 (1949). The Second Sex (New York: Vintage).

Dean, Jodi. 1996. Solidarity of Strangers: Feminism after Identity Politics (Berkeley: University of California Press).

Ferguson, Ann. 2009. 'Feminist paradigms of solidarity and justice', Philosophical Topics, 37(2): 161-77.

Fraser, Nancy. 1986. 'Toward a discourse ethic of solidarity', Praxis International, 5(4), 425-9.

Given, Lisa M. (ed.). 2008. The Sage Encyclopedia of Qualitative Research Methods (Los Angeles, CA: Sage Publications).

Gray-Rosendale, Laura, and Gil Harootunian (eds.). 2003. Fractured Feminisms: Rhetoric, Context, and Contestation (Albany: State University of New York Press).

Hames-García, Michael Roy, and Ernesto Javier Martínez (eds.). 2011. Gay Latino Studies: A Critical Reader (Durham, NC: Duke University Press).

Haslanger, Sally Anne. 2012. Resisting Reality:
Social Construction and Social Critique (New York: Oxford University Press).

hooks, bell. 2015. Feminist Theory: From Margin to Center (New York: Routledge).

McAfee, Noëlle. 2018. 'Feminist philosophy', in The Stanford Encyclopedia of Philosophy, <https://plato.stanford.edu/archives/ fall2018/entries/feminist-philosophy> (accessed 1.8.2020).

Mascia-Lees, Frances E., and Patricia Sharpe. 2000. Taking a Stand in a Postfeminist World: Toward an Engaged Cultural Criticism (Albany: State University of New York Press).

Mohanty, Chandra. 1988. 'Under western eyes: feminist scholarship and colonial discourses', Feminist Review, 30: 65-88.

Mohanty, Chandra Talpade. 2003. Feminism without Borders: Decolonizing Theory, Practicing Solidarity (Durham, NC: Duke University Press).

Pal, Carol. 2012. Republic of Women: Rethinking the Republic of Letters in the Seventeenth Century (Cambridge University Press).

Rich, Adrienne. 2003 (1984). 'Notes towards a politics of location', in Feminist Postcolonial Theory: A Reader, eds. Reina Lewis and Sara Mills (New York: Routledge), 29-42.

Ricoeur, Paul. 2016. Hermeneutics and the Human Sciences: Essays on Language, Action, and Interpretation (Cambridge University Press).

Scholz, Sally J. 2008. Political Solidarity (University Park: Pennsylvania State University Press).

Scholz, Sally J., and Shannon M. Mussett (eds.). 2005. The Contradictions of Freedom: Philosophical Essays on Simone de Beauvoir's The Mandarins (Albany: State University of New York Press).

Simms, Karl. 2002. Paul Ricoeur (Oxford: Taylor and Francis). 